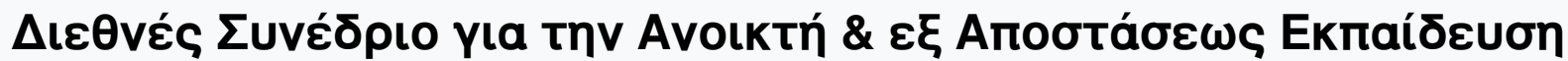

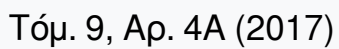

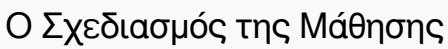

Tópos 4, Mépos A

\section{Практіка́}

$9 \circ \Delta ı$ เ

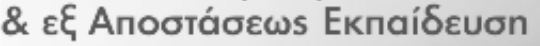

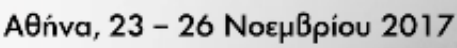

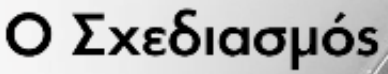 ins MáӨnons}

Enıนédeıa

Avióvns Aıvapákns

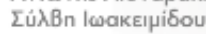

Mapia Niápn

Гке́̉n Mavoúoou

Tóvia Xaproqúdara

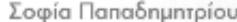

Avva Anoorodibou

ISBN 978-618-82258-9.3

ISBN SET 978-618-82258-5-5

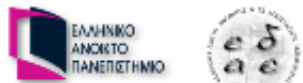

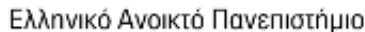

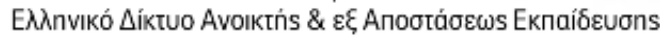

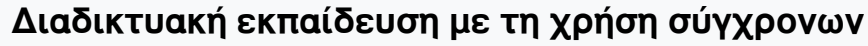

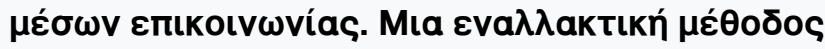

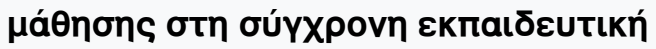

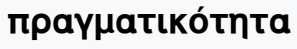

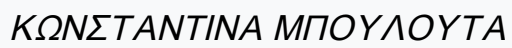

doi: $10.12681 /$ icodl. 1068 


\title{
Online education with modern communication media. An alternative learning process in the modern educational reality
}

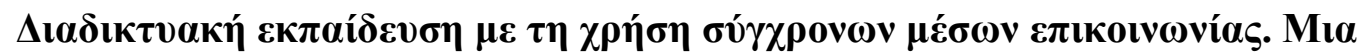

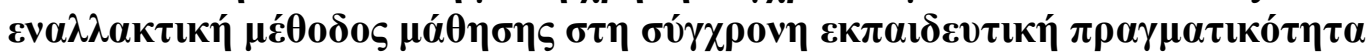

\author{
Konstantina Boulouta \\ Phd candidate \\ Computer Engineering \& Informatics Department \\ University of Patras \\ bouconsta@gmail.com
}

\begin{abstract}
Modern socio-economic-cultural environment is characterized by the huge volume, the variety of available digital information with the Internet being an integral part of modern's people everyday life and especially that of the new generation. Extend use of new technologies and the digital generation that emerged through, have affected the education sector in such a point that is now under research whether social networks should be used in the whole learning process. Social networks shape the new learning needs and challenges within the "digital" learning environment. They are used as cognitive tools that contribute to the formation of knowledge with combination of text, video and audio. The purpose of this study is to highlight the role of digital technologies in Institutions of higher education around the world and in Greece too. For this a quantitative research conducted using questionnaire as the main tool, in three Greek Universities: Piraeus University of Applied Sciences, Hellenic Open University and TEI of Epirus. The sample of undergraduates and postgraduates students and the results revealed how an asynchronous application system Moodle, not only encourages students in the continuation of their studies but helps the distance education. Problems of course have to be investigated, with recommendations for improvement measures.
\end{abstract}

Keywords: New technologies in higher education, digital generation, Moodle

\section{Пєрí $\eta \psi \eta$}

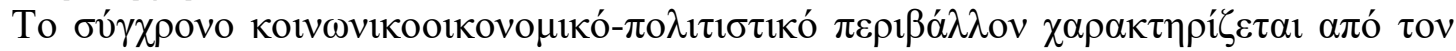

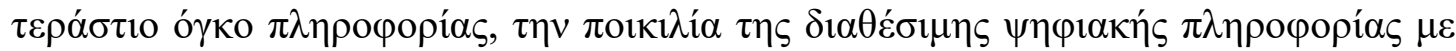

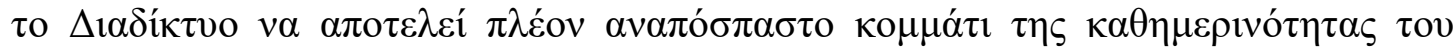

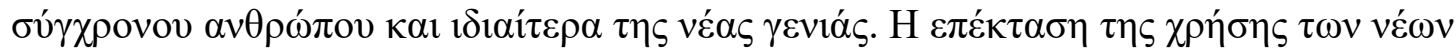

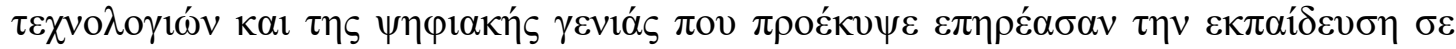

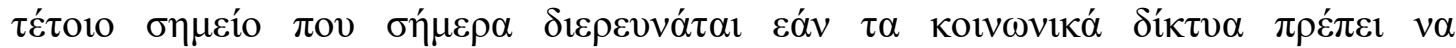

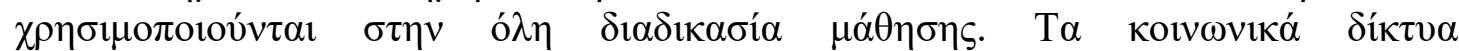

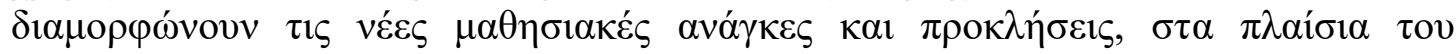

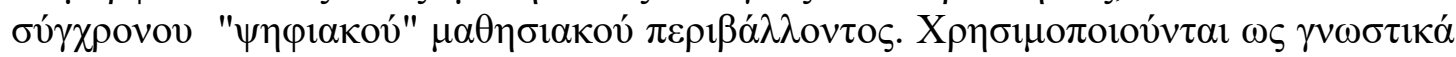

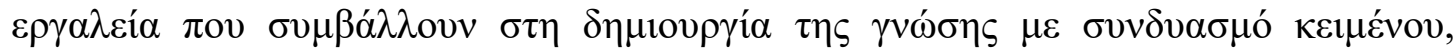

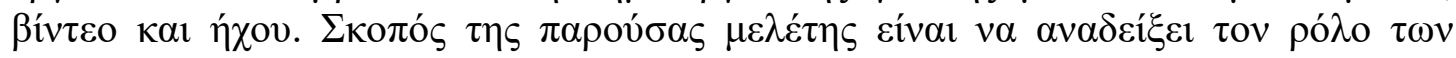

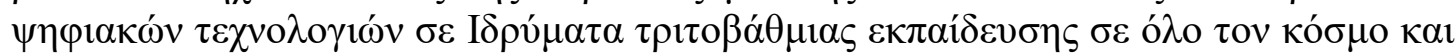




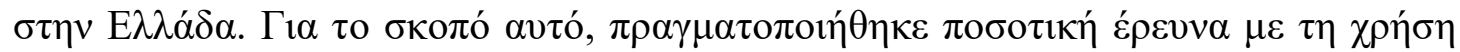

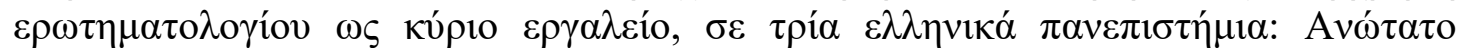

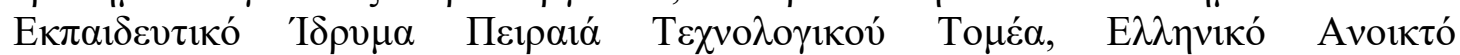

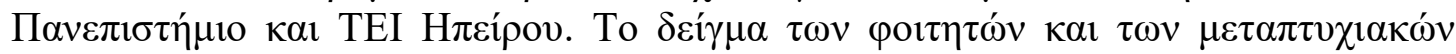

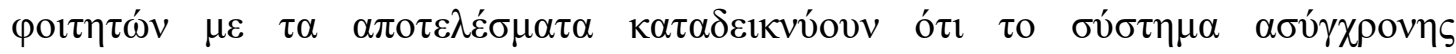

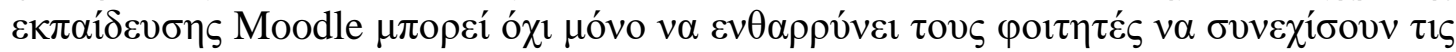

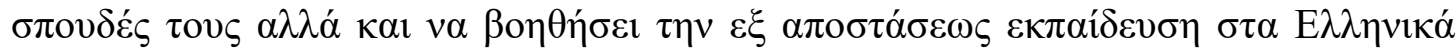

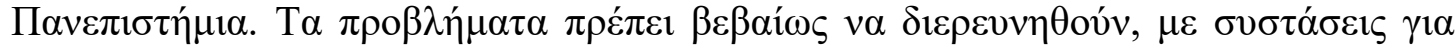
$\mu \varepsilon ́ \tau \rho \alpha \beta \varepsilon \lambda \tau i ́ \omega \sigma \eta \varsigma$.

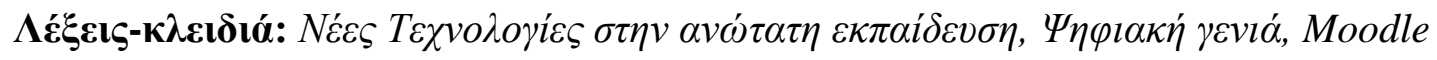

\section{Introduction}

New technologies are developing every day, and in combination with globalization and economic changes that take place, they provide even more profound changes that will affect future lives of all people, regardless of their gender (Beetham \& Sharpe, 2013). New generation ought to cultivate digital skills, beyond other skills, as they seem to be essential in an ever-evolving society. New demands and challenges are set in the education sector, strengthening the classical learning environment with alternative ways of learning. However, the introduction of social networks into traditional institutions is a part of a complex process / innovation, which should be considered as work in progress and a challenge for policy-makers, both locally and internationally.

This paper hopes to contribute substantially in exploring the role of social networks and how they are used by teachers and students at all levels of educational process. More than a billion individuals around the world and in Greece too, are connected and networked everyday together to create, collaborate, and contribute their knowledge and wisdom. A quantitative research using questionnaire as a main tool conducted in three specific Greek universities, the Piraeus University of Applied Sciences, Hellenic Open University and TEI of Epirus. The sample of undergraduates and postgraduates students and the results show that Moodle is a new online learning tool which encourages them in the continuation of their studies. Problems of course have to be investigated, with recommendations for improvement measures. It revealed that students consider Moodle an easy platform, as it does not require specialized knowledge on how to use it, complementary to the classical educational process. Women evaluate it higher in comparison to men. Finally the inclusion of New Technologies in Education is a new reality taking every day new dimensions and of course new fields have to be explored.

\section{"Network" learning process through New technologies}

The revolution in the field of new technologies and information, has initiated by the invention of communication devices (telegraph, telephone and radio) that prepared the advent of the computer. Computer is called the device, "which solves problems by applying predefined functions on information or data imported into it, data is treated with absolute precision and speed, without the need for human intervention" (Golikidou \& Tzimogiannis, 2013). After computer's discovery, the next greatest technological revolution was the emergence of the internet. Internet enables people to access a wealth of material, to give and take information, while promoting 
cooperation and communication between people living in different geographic areas (Boyd, 2007).

The entrance of new technologies in education, created a new learning environment, where student holds the central role. Teacher's role in the introduction of ICT in education changes as the teacher does not transmit only knowledge anymore. He is the facilitator who organizes the learning process. Based on this the teacher becomes the mediator of knowledge and the student is the contributor who uses new technologies to gain knowledge. This method of learning requires new forms of monitoring and evaluation. The teacher is the leader and the expert to whom students turn into when they need it (Beetham \& Sharpe, 2013).

Students have the opportunity to learn anytime, anywhere as learning using new technologies can take place via mobile devices, offering flexibility in time and in the place of learning. At the same time ICT make it possible to combine acoustic and visual information through the use of video in presentations. Also short text messages via mobile phones are gaining more and more in use as they can be much larger than emails (Mao, 2014).

The ICT learning nowadays plays an important role for current students' personal value. According to Jimoyianni and Komi (2007), new technologies are a potential communicative learning tool for the student. Online communication promotes interaction, which is preferred mostly by young people. ICT also offer tools that help students to control their learning environment and their learning experience. Because of personality's anonymity in groups, students are encouraged to better participate in social negotiations that distinguish the structure of knowledge. Students have the opportunity to choose whether to participate or not in a discussion. They also have the opportunity to interact without restrictions by offering the possibility to teachers for time lag required to participate in the discussion with a considered response (Sánchez et al., 2014).

Communication through ICT offers also similar advantages for teachers. Specifically, teachers have the option to choose either a group of students or an individual for further discussion that they need or he needs. The ability to build pedagogical communication with this targeted way is significantly enhanced in many online environments, and could have many benefits when students are of different age and prior experience (Beetham \& Sharpe, 2013).

Based on the above it is concluded that ICT is a prerequisite for communication between teachers and students, and between students themselves. Alongside ICT is a prerequisite for finding, obtaining and processing the necessary information. Specifically through internet the student obtains a wealth of information, with the help of appropriate educational software which deepens and enriches the module, he has processed. Likewise teamwork promoted by new technologies help students to produce their own new material on the basis of what they have been taught. Finally the student becomes familiar with the new technologies that will form an integral part of his everyday life.

The rise of Internet technologies and online communication has changed the way students work, communicate, socialize and learn as «network society» (Beetham \& Sharpe, 2013). Online social networks are an excellent communication tool for the construction of knowledge based on social relationships, conversation, cooperation and joint work (Arroyo, 2011). Effective teachers should become network administrators, in order to learn the social networking sites that are used by students and introduce them to learning opportunities through useful websites (Saeed et al., 2009). 


\section{Methodology}

The research methodology was based on the collection of primary and secondary data collected through books, articles in journals and through official websites. The primary data were collected by conducting a quantitative research using questionnaire as the main tool. The results highlight how the Moodle helps the online distance learning in these specific universities, investigate any problems and make recommendations with improvement measures for a more qualitative learning.

\section{Sample}

A convenience sample of 112 students undergraduates and postgraduates was selected, from the Piraeus University of Applied Sciences, the Hellenic Open University and the TEI of Epirus. The proportion of men and women in the sample was $57.1 \%$ and $42.9 \%$ respectively. In addition, $22.3 \%$ were aged 31 to 35 years old, $21.4 \%$ over 46 years old, $17.9 \%$ from 26 to 30 years old, $14.3 \%$ from 36 to 40 years old, $12.5 \%$ from 18 to 21 years old, $5.4 \%$ from 22 to 25 years and the remaining $6.3 \%$ from 41 to 45 years old. Finally, $32.1 \%$ were graduates of colleges, $33 \%$ were university graduates, $18.8 \%$ had a master's degree, $12.5 \%$ were high school graduates and $3.6 \%$ were holders of a $\mathrm{PhD}$.

\section{Reliability}

To control the reliability of the questionnaire, index Cronbach's alpha was used. The price for the questions relating to moodle's evaluation was equal to 0.860 and this is very satisfying.

\section{Statistical analysis}

Descriptive statistics was used to capture the demographic characteristics and the answers given by respondents. Moreover inferential statistics was used to investigate the effect of gender and education in moodle's evaluation. The statistical program SPSS 17.0 was used to perform the statistical analysis of data.

\section{Results}

For the section where respondent answers were given descriptively, using frequencies and percentages, it can be observed that students can manage and at a very good extent benefit from using Moodle. According to their opinion, it is an easy tool to use that helps them in their academic life while it can increase their performance. Probably some students need further training or available textbooks/manuals to facilitate even more Moodle's use, particularly students who are not so familiar with such technology.

Table 1 Evaluation of the Moodle

\begin{tabular}{|c|c|c|c|c|c|c|c|c|c|c|}
\hline & \multicolumn{2}{|c|}{$\begin{array}{l}\frac{c}{U} \\
\text { J } \\
\text { E } \\
\frac{\lambda}{d}\end{array}$} & \multicolumn{2}{|r|}{ 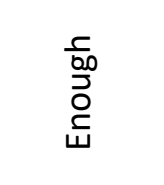 } & \multicolumn{2}{|c|}{ 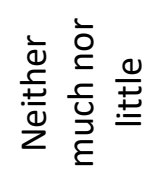 } & \multicolumn{2}{|r|}{$\frac{\frac{0}{ \pm}}{\frac{ \pm}{\varangle}}$} & \multicolumn{2}{|r|}{$\begin{array}{l}\overline{\bar{\sigma}} \\
+ \\
\ddot{\sigma} \\
\ddot{0} \\
z\end{array}$} \\
\hline & $\mathrm{N}$ & $\%$ & $\mathrm{~N}$ & $\%$ & $\mathrm{~N}$ & $\%$ & $\mathrm{~N}$ & $\%$ & $\mathrm{~N}$ & $\%$ \\
\hline $\begin{array}{l}\ldots . . . \text { It helps as to the way the course } \\
\text { is structured }\end{array}$ & 2 & $1.8 \%$ & 26 & $23.9 \%$ & 36 & $33.0 \%$ & 10 & $9.2 \%$ & 35 & $32.1 \%$ \\
\hline ...... It helps to study the course & 2 & $1.8 \%$ & 52 & $46.4 \%$ & 44 & $39.3 \%$ & 4 & $3.6 \%$ & 10 & $8.9 \%$ \\
\hline
\end{tabular}


course

It helps to understand the

...... It helps to move on to the study

of the subsequent chapters

...... It helps with my contact with the

teacher, facilitates communication

It facilitates the course with

useful multimedia (videos, etc.) $\begin{array}{llllllllll}2 & 1.8 \% & 38 & 33.9 \% & 46 & 41.1 \% & 14 & 12.5 \% & 12 & 10.7 \%\end{array}$

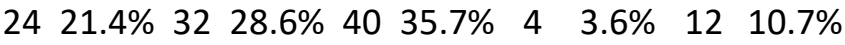

$21 \quad 18.8 \% \quad 47 \quad 42.0 \% \quad 32 \quad 28.6 \% \quad 10 \quad 8.9 \% \quad 2 \quad 1.8 \%$

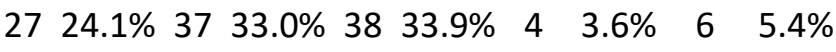

According to Table 1, 60.8\% of students reported that Moodle helps at least enough to be in contact with the teacher and facilitates their communication, while $57.1 \%$ reported that it facilitates the course with its useful multimedia, and $50 \%$ reported that it helps them to continue the study of the following chapters. Also, $48.2 \%$ reported that it helps them to study the course, $35.7 \%$ said that it helps them to understand the course and $25.7 \%$ said that it helps them how the course is structured. Based on the above students responses, it can be concluded that Moodle is evaluated as quite useful in terms of contact with the teacher, the study of the following chapters and the course study. Furthermore it helps some of the students to understand the course and also on how the course is structured. Therefore, in general, Moodle is considered to be a quite useful tool in specific areas that mainly concern the study and organization of the course.

Table 2 Differences in the evaluation of the Moodle between men and women

\begin{tabular}{|c|c|c|c|c|c|c|}
\hline & \multicolumn{4}{|c|}{ Gender } & \multirow[b]{3}{*}{$u$} & \multirow[b]{3}{*}{$P$} \\
\hline & \multicolumn{2}{|c|}{ Male } & \multicolumn{2}{|c|}{ Female } & & \\
\hline & M & SD & M & SD & & \\
\hline ...... It helps as to the way the course is structured & 3.72 & 1.31 & 3.13 & 1.02 & 1078.000 & $.014^{*}$ \\
\hline ...... It helps to study the course & 2.78 & .93 & 2.63 & .91 & 1324.000 & .173 \\
\hline ...... It helps to understand the course & 3.13 & 1.03 & 2.75 & .89 & 1180.000 & $.026^{*}$ \\
\hline $\begin{array}{l}\text {..... It helps to move on to the study of the } \\
\text { subsequent chapters }\end{array}$ & 2.72 & 1.13 & 2.29 & 1.22 & 1204.000 & $.042 *$ \\
\hline $\begin{array}{l}\text {..... It helps with my contact with the teacher, } \\
\text { facilitates communication }\end{array}$ & 2.45 & 1.02 & 2.17 & .81 & 1318.000 & .176 \\
\hline $\begin{array}{l}\text {....... It facilitates the course with useful } \\
\text { multimedia (videos, etc.) }\end{array}$ & 2.30 & .97 & 2.38 & 1.16 & 1528.000 & .961 \\
\hline
\end{tabular}

Note: ${ }^{*} \mathrm{p}<.05, \mathrm{M}=$ mean value, $\mathrm{SD}=$ standard deviation, $\mathrm{U}=$ Mann Whitney value, $1=$ Very much, $5=$ Not at all,

According to Table 2 and the Mann Whitney test, women evaluate the Moodle higher than men in that it helps them in the way the course is structured $(p=.014)$, in understanding the course $(p=.026)$ and to proceed the study of the following chapters ( $p$ $=.042$ ). 
Table 3 Differences in assessment of Moodle between levels of education

\begin{tabular}{|c|c|c|c|c|c|c|c|c|c|c|}
\hline & \multicolumn{8}{|c|}{ Education } & & \multirow[b]{3}{*}{$\mathrm{p}$} \\
\hline & \multicolumn{3}{|c|}{ 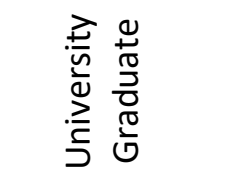 } & \multicolumn{2}{|l|}{$\underset{⿱ 亠 䒑}{\stackrel{\frac{\pi}{J}}{\frac{\pi}{0}}}$} & \multicolumn{2}{|l|}{ 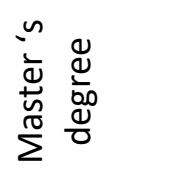 } & \multicolumn{2}{|l|}{$\begin{array}{l}\stackrel{0}{ \pm} \\
\stackrel{0}{T} \\
\frac{7}{0} \\
\frac{\pi}{0}\end{array}$} & \\
\hline & $\mathrm{M}$ & TA & $\mathrm{M}$ & TA & M & TA & $\mathrm{M}$ & TA & $x^{2}(3)$ & \\
\hline ......helps with course's structure & $\begin{array}{c}4.0 \\
0\end{array}$ & $\begin{array}{c}1.1 \\
3\end{array}$ & $\begin{array}{c}2.8 \\
1\end{array}$ & 1.01 & $\begin{array}{c}3.6 \\
7\end{array}$ & 1.28 & $\begin{array}{c}3.7 \\
1\end{array}$ & 1.20 & 17,908 & 000 \\
\hline .....helps to study the course & $\begin{array}{c}3.0 \\
5\end{array}$ & .97 & $\begin{array}{c}2.4 \\
2\end{array}$ & .77 & $\begin{array}{c}2.3 \\
8\end{array}$ & .50 & $\begin{array}{c}3.2 \\
9\end{array}$ & 1.20 & 15,429 & 001 \\
\hline $\begin{array}{l}\text {.....helps to understand the } \\
\text { course }\end{array}$ & $\begin{array}{c}3.2 \\
4\end{array}$ & $\begin{array}{c}1.0 \\
4\end{array}$ & $\begin{array}{c}2.6 \\
7\end{array}$ & .86 & $\begin{array}{c}3.2 \\
4\end{array}$ & 1.22 & $\begin{array}{c}2.8 \\
6\end{array}$ & .36 & 5,759 & 124 \\
\hline $\begin{array}{l}\text {......helps to continue the study } \\
\text { of the following chapters }\end{array}$ & $\begin{array}{c}3.1 \\
4\end{array}$ & $\begin{array}{c}1.4 \\
6\end{array}$ & $\begin{array}{c}2.2 \\
5\end{array}$ & 1.00 & $\begin{array}{c}2.2 \\
4\end{array}$ & .70 & $\begin{array}{c}2.4 \\
3\end{array}$ & .94 & 8,292 & 040 \\
\hline $\begin{array}{l}\text {.....helps in my contact with the } \\
\text { teacher, facilitates the } \\
\text { communication }\end{array}$ & $\begin{array}{c}2.1 \\
9\end{array}$ & $\begin{array}{c}1.1 \\
7\end{array}$ & $\begin{array}{c}2.3 \\
9\end{array}$ & .99 & $\begin{array}{c}2.3 \\
8\end{array}$ & .50 & $\begin{array}{c}2.5 \\
7\end{array}$ & .76 & 3,738 & 291 \\
\hline $\begin{array}{l}\text {......facilitates the course with } \\
\text { useful multimedia (video, etc.) }\end{array}$ & $\begin{array}{c}2.4 \\
3\end{array}$ & $\begin{array}{c}1.4 \\
1\end{array}$ & $\begin{array}{c}2.1 \\
9\end{array}$ & .98 & $\begin{array}{c}2.3 \\
8\end{array}$ & .50 & $\begin{array}{c}2.5 \\
7\end{array}$ & .76 & 2,594 & ,459 \\
\hline
\end{tabular}

1=very much, 5=not at all

According to table 3 and Kruskal Wallis test, University graduates evaluate higher Moodle in comparison to other educational levels as it helps on how the course is structured $(\mathrm{p}=.000)$, in their study for the course $(\mathrm{p}=.001)$ and to continue in the study of the following chapters $(\mathrm{p}=.040)$.

\section{Conclusions}

Greek society has transformed into an information society (Lockwood, 2013). Distance learning helps the lifelong learning of the individual to gain further skills essential for the society in which he continually evolves. New Technology's integration into education facilitates the active engagement of learners and their participation in knowledge, enriches their learning experience, and contributes to the acquisition of new skills and attitudes. Everyone has to cultivate beyond his other skills, digital skills that respond to the needs of today's society. However, the introduction of social networks into traditional institutions is a part of a complex process / innovation, which should be considered as an ongoing work and challenge for policy-makers at both local and international level.

The above analysis showed that the vast majority of students agreed that through Moodle they can easily access its contents and browse it freely, without having someone to explain them how it works. This platform has many advantages and any problems arising can be resolved. It is concluded that Moodle is generally an easy platform to use, for students who do not require specialized knowledge on how to use it. Students considered that Moodle has many advantages for their learning as it is easy to acquire material from the Moodle and as reported they can use the Moodle if there are textbooks available. Therefore Moodle is an effective learning platform for distance learning and the ease of using it in distance learning programs is an important 
factor that encourages students and also in the continuation of their studies. The use of new technologies should not replace under any circumstance teachers role or books but help students to actively participate in the learning process.

\section{References}

Arroyo, C.G. (2011). On-Line Social Networks: Innovative Ways towards the Boost of Collaborative Language Learning, available at: http://conference.pixelonline.net/ICT4LL2011/common/download/Paper_pdf/CLL16-428-FP-Gonzalez-

ICT4LL2011.pdf (accessed 10 March 2017).

Beetham, H., \& Sharpe, R. (2013). Rethinking pedagogy for a digital age: Designing for 21 st century learning. Routledge.

Boyd D. (2007). Why Youth (Heart) Social Network Sites: The Role of Networked Publics in Teenage Social Life,[w:] Buckingham D.(red.). Mc Arthur Foundation on Digital Learning-Youth, Identity, and Digital Media Volume. 2007:1-26.

Boyd, D. M., and Ellison N. B. (2007) Social Network Sites : Definition, history and scholarship, Journal of Computer Mediated Communication, 13(1), article 11

Jimoyiannis, A., Komis, V. (2007). Examining teachers' beliefs about ICT in education: implications of a teacher preparation programme. Teacher Development 11(2), 149-173.

Lockwood, F. (2013). Open and distance learning today. Routledge.

Mao, J. (2014). Social media for learning: A mixed methods study on high school students' technology affordances and perspectives. Computers in Human Behavior, 33, 213-223.

Saeed, N., Yang, Y., \& Sinnappan, S. (2009). Emerging web technologies in higher education: A case of incorporating blogs, podcasts and social bookmarks in a web programming course based on students' learning styles and technology preferences. Educational Technology \& Society, 12(4), 98-109.

Sánchez, R. A., Cortijo, V., \& Javed, U. (2014). Students' perceptions of Facebook for academic purposes. Computers \& Education, 70, 138-149.

Giolikidou, L.\&Gimogiannis, A. (2013). Design and Study of a Electronic Learning Distance Program from within a Comenius project. [in Greek]. 